Viñas-Diez V, Turró-Garriga O, Portellano-Ortiz C, Gascón-Bayarri J, Reñé Ramírez R, Garre-Olmo J, Conde-Sala JL. Kinship and cohabitation in relation to caregiver burden in the context of Alzheimer's disease: a 24-month longitudinal study. International Journal of Geriatric Psychiatry 2017. doi: 10.1002/gps.4656 (on-line)

http://onlinelibrary.wiley.com/doi/10.1002/gps.4656/full

\title{
Kinship and cohabitation in relation to caregiver burden in the context of Alzheimer's disease: a 24-month longitudinal study
}

\section{Authors and affiliation}

Vanesa Viñas-Diez ${ }^{1}$, Oriol Turró-Garriga ${ }^{2,3}$, Cristina Portellano-Ortiz ${ }^{4}$, Jordi GascónBayarri $^{1}$, Ramón Reñé-Ramírez ${ }^{1}$, Josep Garre-Olmo ${ }^{2,5}$ and Josep Lluís Conde-Sala ${ }^{2,4}$ *

${ }^{1}$ Dementia Unit, Department of Neurology, Bellvitge University Hospital, Hospitalet de Llobregat, Catalonia-Spain

${ }^{2}$ Health, Aging and Disability Research Group, Girona Biomedical Research Institute (IDIBGI), Girona, Catalonia-Spain

${ }^{3}$ Department of Neurology, Institut d'Assistència Sanitària-Institut Català de Salut de Girona, Salt, Catalonia-Spain

${ }^{4}$ Faculty of Psychology, University of Barcelona, Barcelona, Catalonia-Spain

${ }^{5}$ Department of Medical Sciences, University of Girona, Girona, Catalonia-Spain

* Correspondence to: Dr. J. Lluís Conde-Sala, Faculty of Psychology, University of Barcelona, Passeig Vall d'Hebron, 171, 08035 Barcelona, Spain

E-mail address: jllconde@ub.edu Tel. (+34) 933125814

\section{Key points}

- The results of the longitudinal analysis established a greater burden (ZBI) on live-in adult-child caregivers, and a smaller burden on non-live-in adult-child caregivers, with stable scores on the follow-up for both groups. Spouses had a low burden in the early stages, with a significant increase during the follow-up.

- Variations between spouses and adult-child caregivers are attributable to the different nature of the marital and child-parent relationship, and to the cohabitation factor.

- The different types of caregivers have relevant socio-demographic and clinical features which help to characterize them: gender, cohabitation with persons with dementia, education, marital status, sole caregiver or not sole caregiver, and the use of external resources.

Funding: This study was partially conducted within the framework of the project: Assessing perceptions of patient quality of life in patients with Alzheimer's disease and their family caregivers over a two-year period, funded by Spain's Ministry of Economy and Competitiveness (ref: PSI2010-19014).

Words. Abstract: 246; text: 3,504; tables: 5; figure: 1 


\section{Abstract}

Objectives: The aims of the study were to identify the clinical characteristics of three groups of caregivers: spouses, live-in adult-child or non-live-in adult-child, and their relation to the degree of perceived burden (Caregiver Burden Interview).

Methods: The sample comprised 275 Alzheimer's disease (AD) primary caregivers, with a follow-up of 24 months. Cognitive, functional and behavioural characteristics were evaluated in persons with $\mathrm{AD}(\mathrm{PwD})$, while socio-demographic data, use of socio-medical resources, physical and mental health, and self-perceived burden were assessed in caregivers. Generalized estimating equations (GEE) were used for longitudinal data analysis.

Results: Spouse caregivers were $45.0 \%$ men, sole caregivers (> 80\%), used few external resources, and had worse physical health. The number of female adult-child caregivers was higher (>75\%). The live-in adult-child group, compared with the non-live-in adult-child group, were less likely to be married, had a lower level of education, were more commonly the sole caregiver, and used fewer external resources. The greatest burden was observed in live-in adult-child caregivers, and the lowest in the non-live-in adult-child group, with no significant variation in the follow-up for both groups. Spouses had an intermediate level of perceived burden, which rose significantly during follow-up $(p<0.001)$.

Conclusions: Kinship and cohabitation with the PwD were associated with different scores and evolution of the burden, with an increase in the follow-up of the spouses, and with more or less burden, depending on cohabitation, in the adult-child groups. Interventions to reduce the level of burden on caregivers should consider these differences.

Keywords: Alzheimer’s disease, burden, family caregivers, kinship, cohabitation 


\section{Introduction}

Alzheimer's disease (AD) is the most common cause of dementia in Western societies (Jurado et al., 2013). According to the World Alzheimer Report (Prince et al., 2015), it is estimated that there are 46.8 million people with dementia in the world, and each year this number increases by over 9.9 million.

In addition to involving a neurodegenerative process in the patient, this disease is often associated with a burden in family caregivers. The burden is defined as a multidimensional response to physical, psychological, social and economic demands generated by patient care (Etters et al., 2008).

Three types of factors that directly affect the burden have been described: contextual, such as family relations or cohabitation; characteristics related to the patient's disease, such as behavioural disorders or the severity of the dementia; and the caregiver's socio-demographic characteristics, such as sex or age (Kim et al., 2012).

The influence of kinship and cohabitation on the caregiver's burden

Previous studies that assessed the level of burden according to patient-caregiver kinship have shown contradictory results. In some research, adult-child caregivers were those with the highest burden levels (Andrén and Elmstâhl, 2007; Molyneux et al., 2008; Chappell et al., 2014). Conversely, other studies observed a greater burden and stress in spouse caregivers (Schulz and Martire, 2004; Park et al., 2015). Finally, other studies found no significant differences overall (Ferrario et al., 2003; Ankri et al., 2005; Turró-Garriga et al., 2008).

In their review, Pinquart and Sörensen (2011) concluded that although there were no differences in overall burden, spouses showed greater physical, financial and relational burden. In adult-child caregivers, a greater emotional and social burden was observed, due to their related job commitments. 
Several studies suggested that female caregivers had a higher burden than men (Rinaldi et al., 2005; Pattanayak et al., 2010; Kim et al., 2012; Park et al., 2015), especially in the spouse group (Reed et al., 2014; Conde-Sala et al., 2010). Other studies have reported more depressive symptoms in female caregivers associated with the burden (Wolfs et al., 2012; Bastawrous et al., 2015).

Use of external resources has also been linked with the caregiver's burden. Better health and wellness has been reported in those who receive more external support (Bastawrous et al., 2015) from family, friends or health services (Chappell et al., 2014). Some studies reported that adult-child caregivers receive more help from others and use more community resources than spouses (Winslow, 1997; Robinson et al., 2005).

Regarding cohabitation with the patient, several studies have shown that caregivers living with persons with dementia (PwD) experience a greater burden (Kim et al., 2012; Raccichini et al., 2009; Reed et al., 2014), even after a period of time (Raccichini et al., 2015). In a previous study, it was observed that kinship and cohabitation characteristics of caregivers were independent factors in the perception of burden and its evolution (Conde-Sala et al., 2014).

\section{Specific burden factors}

Since burden is a multidimensional entity, various factorial analyses of the Caregiver Burden Interview (ZBI) (Zarit et al., 1986) have been carried out. The results indicate that adult-child caregivers have greater feelings of guilt than spouses (Ankri et al., 2005; Turró-Garriga et al., 2008; Sanders et al., 2008), particularly the non-live-in adult-child group (Conde-Sala et al., 2010). In addition, living with the patient involved a greater physical burden (Raccichini et al., 2009). Over time, this increased the global, social and emotional burden caused by patient care (Raccichini et al., 2015). 


\section{Hypothesis and objectives of the present study}

Based on previous studies, the main hypothesis was that cohabitation and a family relationship between PwD and their caregivers have an impact on caregiver burden.

The main objectives were: 1) to identify the clinical and socio-demographic characteristics of each primary caregiver group (spouses, live-in adult-child and non-live-in adult-child) and their relation to the degree of perceived burden; 2) to analyse the influence of clinical and socio-demographic variables on the evolution of the overall burden, according to the caregiver's kinship and cohabitation; 3) to assess specific factors influencing the burden of each group of caregivers, based on the factorial structure of the ZBI.

\section{Methods}

\section{Design and study population}

A 24-month follow-up longitudinal study was performed in a consecutive sample of family caregivers of persons diagnosed with $\mathrm{AD}$, according to the criteria of the Diagnostic and Statistical Manual of Mental Disorders (DSM-IV-TR) (American Psychiatric Association, 2000); and persons with probable AD, according to the criteria of the National Institute on Aging and the Alzheimer's Association (McKhann et al., 2011).

The sample consisted of 275 family caregivers of PwD who were treated as outpatients. A total of 124 were assessed by the Unit of Diagnosis and Treatment of Dementia in the Neurology Department of Bellvitge University Hospital (Hospitalet de Llobregat, Barcelona) and 151 PwD were evaluated in the Unit of Memory and Dementia Assessment of the Santa Caterina Hospital (Salt, Girona). 
The exclusion criteria for PwD were: 1) presence of several communication problems, 2) presence of any other neurological disease or acquired brain damage, and 3) abuse of drugs and/or alcohol.

All selected caregivers were first-degree relatives (spouses or adult-child), who regularly assisted with the patient's activities of daily living (ADL) and continuously supervised their situation as they were the primary caregivers. All spouse caregivers lived with the patient. Some adult-child caregivers lived with the patient, others did not. Thus, the sample was formed of three groups of caregivers.

The study was approved by the ethics committees of the Bellvitge University Hospital and the Healthcare Institute (Santa Caterina Hospital). PwD and caregivers agreed to participate through the informed consent document.

\section{Measures}

- Socio-demographic data. Socio-demographic data on family caregivers (age, gender, marital status, level of education, kinship, cohabitation with the patient, employment status and use of external resources: home help and day care centre) were collected using a structured questionnaire designed ad hoc.

- Assessment of caregiver burden. The Caregiver Burden Interview (ZBI; Zarit et al., 1986) was used to assess the primary caregiver’s burden. This self-administered questionnaire consists of 22 Likert items with the responses: never (1), rarely (2), sometimes (3) several times (4), almost always (5). The total score ranges from 22 to 110 points, and a higher score implies a greater burden. For the burden factorial analysis, 5 factors were used that were identified by Turró-Garriga et al. (2008).

- Caregiver's health assessment. The Short Form-12 Health Survey (SF-12; Ware et al., 1996) was administered to the primary caregiver. This is an abbreviated version of the 
SF-36 Health Survey. It consists of 12 items and the score ranges from 12 to 28 points. Two dimensions are extracted from this questionnaire: physical and mental health. A higher score means better perceived health.

- Cognitive patient's assessment. The Mini-Mental State Examination (MMSE; Folstein et al., 1975) was administered to the PwD. This is a brief cognitive exam with a score ranging from 0 to 30. A lower score corresponds to greater cognitive impairment. A score correction for the Spanish population was used, according to age and level of education (Blesa et al., 2001).

- Functional patient's assessment. The patient's functional capacity was evaluated using the Disability Assessment of Dementia scale (DAD; Gélinas et al., 1999). This scale consists of 40 items: 17 refer to basic activities of daily living (ADL) and 23 to instrumental activities. The score ranges from 40 to 80 points. A higher score implies greater patient autonomy.

- Psychological and behavioural symptoms assessment. Psychological and behavioural symptoms were assessed using the Neuropsychiatric Inventory (NPI; Cummings et al., 1994). It is applied to the primary caregiver and consists of 12 subscales. The score ranges from 0 to 144 points. The higher the score, the higher the number of symptoms presented by the patient

- $\quad$ Stage of dementia. The criteria applied here were those of the Global Deterioration Scale (GDS). This is a clinical assessment scale designed to determine the stage of a patient's dementia (Reisberg et al., 1982).

\section{Procedure}

PwD and caregivers were selected by the Dementia Unit's neurologists, based on the defined inclusion criteria. The selection took place between January 2011 and May 2014. 
The initial study sample consisted of 505 PwD and their caregivers, 275 of whom completed the assessment at 12 and 24 months. There were 230 missing cases (PwD and caregivers): 64 decided not to participate in the follow up, 39 were admitted to residence, 64 suffered severe cognitive impairment, 12 changed their address and 51 died.

Both PwD and caregivers were interviewed individually and separately by two clinical psychologists trained in the administration of the tests.

\section{Statistical analysis}

To compare the baseline variables, including lost cases and those of subjects who completed the study, the chi-square $\left(\chi^{2}\right)$ statistical test was used for categorical variables and the Mann-Whitney (z) test for quantitative variables.

For the longitudinal data analysis, generalized estimating equations (GEE) and the Wald $\chi 2$ statistic were applied (Liang and Zeger, 1986; Zeger et al., 1988), in conjunction with a first-order autoregressive working correlation matrix (AR1). This model allowed us to examine the general effects of the independent variables on the main variable, in terms of the factors of time and groups of caregivers and the interaction between factors (time $\mathrm{x}$ group), and to observe the simple effects of differences between groups.

To assess the magnitude of the effect of the difference between the proportions, we used Cramer's V (V), whose values depend on the degrees of freedom (Cohen, 1988). Eta squared ( $\eta 2)$ was used to assess the effect size of the difference between several means. Its values indicate weak $(<0.05)$, moderate $(0.06-0.13)$ or high $(>0.14)$ effects (Cohen, 1973).

For the factorial analysis of the Caregiver Burden Interview (ZBI), we used the results of a study by Turró-Garriga et al. (2008), which identified five factors: Factor 1: Social and Physical (items 2, 3, 6, 10, 11, 12, 13, 17), Factor 2: Anxiety (items: 15, 16, 18, 19), Factor 3: Guilt (items 20, 21), Factor 4: Irritation (items 4, 5, 9), Factor 5: Dependence (1, 7, 8, 14). 
A multivariate analysis was performed to find out which factors were most involved in each group of caregivers' burden. The model was adjusted with the patient's clinical variables.

All data were analysed using SPSS, version 22 (IBM Corp. Armonk, NY). The level of significance for comparisons was $p<0.05$.

\section{Results}

\section{Sample description}

Clinical and socio-demographic data of the lost cases. A total of 230 of the 505 baseline cases were lost during the follow-up. The characteristics related to loss of patients were older age and greater cognitive, functional and behavioural impairment. For caregivers, withdrawalrelated factors were younger age, being an adult-child caregiver and having the greatest baseline burden. The differences between the follow-up and lost cases are shown in Table 1.

\section{Table 1}

Caregivers' socio-demographic data. The study sample consisted of $275 \mathrm{PwD}$ and their caregivers, who completed the study at baseline, 12 and 24 months.

At baseline, 153 caregivers were spouses, of whom approximately half (54.9\%) were women. There was a higher percentage of women in the adult-child groups (non-cohabiting = 75.0\%; cohabiting $=75.9 \%)$. Spouse caregivers $(55.7 \%)$ were older, had a lower level of education and were more frequently sole caregivers (87.6\%). All spouse caregivers cohabited with the patient.

Live-in adult-child caregivers (19.6\%) had a lower level of education and were more often sole and unmarried caregivers. Non-live-in adult-child caregivers (24.7\%) were more likely to be married, had more children at home, were more likely to work outside the home 
and tended to use more external resources (39.7\%), although the differences were not always significant. Table 2 shows the caregivers’ socio-demographic characteristics.

Table 2

\section{Caregivers’ clinical data during follow-up}

When the caregiver-perceived burden was analysed, it was seen to be significantly higher in the live-in adult-child group and remained stable during follow-up. In the spouse group, the burden was significantly higher at follow-up $(p<0.001)$, but it was always at scores that were in between those of the two other groups. The non-live-in adult-child group experienced the lowest burden, whilst the live-in adult-child group had the greatest burden. There were no differences at follow-up in the adult-child groups $(p=0.103 / p=0.363)$. The effect size of intergroup differences was moderate in the three evaluations $\left(\eta^{2}=0.08\right.$ / 0.08 / 0.07) (Figure 1).

\section{Figure 1}

Although the live-in adult-child showed poorer mental health on the SF-12 survey, there were no significant differences between groups. The effect size of intergroup differences was weak for the three evaluations $\left(\eta^{2}=0.01 / 0.00\right.$ / 0.01). However, physical health (SF-12) differences were found, and the spouse group had a significantly lower score over the entire follow-up. The effect size of intergroup differences was moderate in the three evaluations $\left(\eta^{2}\right.$ $=0.08 / 0.06 / 0.09)$. Caregivers’ clinical data are presented in Table 3.

\section{Table 3}

\section{Burden-associated factors: multivariate analysis}

A multivariate analysis was performed with burden as the dependent variable and caregivers' socio-demographic and clinical data as independent variables. The model was adjusted with the patients' clinical data (MMSE, DAD and NPI). 
Throughout the study, it was observed in all caregiver's groups that worse mental health (SF-12) contributed considerably to a higher burden (especially in the group of adult-child caregivers who cohabited). The association between poorer physical health (SF-12) and burden was more consistent in spouses. The effect of not using external resources and being the sole caregiver was associated with a greater burden on spouses and live-in adult-child caregivers.

Male caregivers also had higher burden levels in the live-in adult-child group at baseline. Older age was associated with a higher burden only in the non-live-in adult-child group. Data are shown in Table 4.

Table 4

\section{Burden analysis according to factorial structure}

When the analysis was performed according to the factorial structure of the burden (TurróGarriga et al., 2008), it was found that the caregivers who had a greater social and physical burden were the groups who cohabited with the patient, especially the adult-child group (Table 5). In the intergroup differences, a moderate effect size was observed in the three evaluations $(\eta 2=0.04 / 0.12 / 0.11)$.

Irritation also remained at higher levels in the live-in groups (spouse and adult-child), although significant differences were only found at 24 months.

The relation of Dependence with the patient was most intense in the spouse group, and least intense in the non-live-in adult-child group.

Although the non-live-in adult-child group showed a tendency to have higher Guilt factor levels, the differences between the three groups were not significant. No significant differences between groups were found for the Anxiety factor.

Table 5 


\section{Discussion}

\section{Differential characteristics between caregivers' groups}

Clinical and socio-demographic differences between the three groups were found. The spouse group tended to be comprised of older people with a lower level of education and worse physical health, more sole caregivers, and more men. In adult-child groups a higher number of female caregivers and a higher level of education were found. The live-in group included fewer married caregivers and more sole caregivers, which could be associated with greater dedication to the patient. Furthermore, a higher level of education and the use of more external resources (home help and day-care centres) were found in the non-live-in adult-child group.

\section{The influence of kinship and cohabitation on caregiver burden}

Our results support the importance of kinship and cohabitation in the determination of caregiver burden. The live-in adult-child caregivers had the greatest burden, while the nonlive-in adult-child group had the lowest burden. These levels remained stable throughout the follow-up. However, spouse caregivers had a lower burden, although the level increased during the follow-up.

These differences between adult-child caregivers and spouses might be related to the caregiver role. In other words, as part of their marriage, spouses are committed to taking care of their family, which could be associated with a lower perceived burden. In contrast, adultchild caregivers may consider that caring for their parent is an added task that leads to major changes in their lifestyle, and a higher burden due to the difficulty of reconciling all their work and family responsibilities (Conde-Sala et al., 2010). 
However, several authors have shown that cohabitation can also play an important role in the perception of burden (Kim et al., 2012; Reed et al., 2014). Taking into account the interaction of these two factors (kinship and cohabitation), our results support the findings of previous studies (Raccichini et al., 2009; Conde-Sala et al., 2014) showing that the burden was higher in the group of live-in adult-child caregivers. This group would be more dedicated to care as they tend to be sole caregivers, less likely to be married, and less likely to use external resources. They adopt roles that are closer to the traditional model of family care, and take responsibility for all the care of the PwD.

Non-live-in adult-child caregivers were those who used more external resources, and experienced least burden in the follow-up. This supports the conclusion of studies indicating that caregivers who receive external support have better health and welfare (Bastawrous et al., 2015; Chappell et al., 2014).

\section{Burden evolution in the follow-up}

Raccichini et al. (2015) considered that live-in adult-child caregivers experienced the same level of burden over time. Our research supports their conclusions, since this group maintained the highest level of burden throughout the follow-up, which was associated with poorer mental health. However, the non-live-in adult-child caregivers was the group that always perceived least burden.

Although the burden remained at intermediate level in the spouse group, it increased over time in the other two groups. Other studies have shown that there may be some adaptation to the care situation that leads to better handling of the burden over time (Riedijk et al., 2008; Wong and Wallhagen, 2012; Chappell et al., 2014). However, our results do not support this conclusion in the case of spouses. In this group, it was observed that worse physical and mental health contributed significantly to increasing the burden, which is probably related 
with older age, deterioration of the patient and the feeling of loss, and an intense, intimate and extensive relationship associated with more depression (Marwit and Meuser, 2002).

Traditional family roles associated with the generational culture and greater interdependence due to years of cohabitation would be stronger in spouses. Non-live-in adultchild caregivers are more likely to be married, have more children and work outside the home. These circumstances may lead to greater distance from the traditional model and the use of more external resources. In contrast, the group of live-in adult-child caregivers tend to have fewer external obligations and probably stronger bonds with their parents, with patterns more in line with the moral obligation to care for their parents.

\section{Specific factors of the burden factor analysis}

We noted that live-in caregivers experienced a higher social and physical burden, and their level of irritation increased over time. These data confirm the results of Raccichini et al. (2015) who showed that cohabitation was associated with a higher social and emotional burden. Cohabitation involves constantly attending to the needs of the PwD, which creates a greater burden and stress.

The spouse group showed strong dependence, whilst the non-live-in adult-child caregivers showed least dependence.

Finally, our results showed no significant differences with respect to guilt, but as in previous studies a tendency to experience more feelings of guilt was detected in the non-livein adult-child group (Turró-Garriga et al., 2008; Conde et al., 2010). This feeling of guilt, which was stronger in the group of children who did not cohabit with the PwD, could be associated with the fact that they could not meet the moral obligation to care for their family according to the traditional model. 


\section{Limitations and future research}

One of the main limitations of this study is the lack of data on the quality of the relationship between the patient and the caregiver prior to the disease, since this aspect could influence the caregiver's perceived burden. An additional limitation, associated with longitudinal studies of patients with $\mathrm{AD}$, is loss of follow-up in older patients and those with more advanced dementia. The lost cases could have generated a greater burden on caregivers.

Another factor that would have been useful to assess is the feeling of satisfaction or wellbeing that may be generated by caring for a loved one. This may play an important role in the experience of caregivers (Bastawrous et al., 2015; Chappell et al., 2015).

\section{Conclusions and clinical implications}

The different scores and burden evolution in the three groups of caregivers indicate that the needs of spouses and adult-child caregivers are different. Therefore, interventions should be adapted to each caregiver, depending on kinship (Reed et al., 2014) and cohabitation. For a non-live-in caregiver, a more informative intervention would be most appropriate (Raccichini et al., 2015). In contrast, for a live-in caregiver, with worse mental health associated with the burden, a more complete intervention would be necessary, in which external resources are implemented in some measure. Spouses do not initially experience a high burden, but this may increase with worsening physical health, deterioration of the patient and the feeling of loss. In this case, a therapeutic intervention, support and socialization over time are required.

\section{Conflict of interest:}

None declared. 


\section{Acknowledgements}

This study was partially conducted within the framework of the project: Assessing perceptions of patient quality of life in patients with Alzheimer's disease and their family caregivers over a two-year period, funded by Spain’s Ministry of Economy and Competitiveness (ref: PSI2010-19014).

\section{Ethical approval}

The study was approved by the Ethics Committee for Clinical Research of the local health authority of Hospital Sta. Caterina (Salt- Spain): SIDEA (Comprehensive Follow-up of Alzheimer's disease) and Bellvitge University Hospital (ref. PR162/10): CUIDA’L-AD (Caregivers of Alzheimer patients). 


\section{References}

American Psychiatric Association. 2000. Diagnostic and statistical manual of mental disorders, DSM-IV-TR. APA Press: Washington, DC.

Ankri J, Andrieu S, Beaufils B, Grand A, Henrard JC. 2005. Beyond the global score of the Zarit Burden Interview: useful dimensions for clinicians. Int. J. Geriatr. Psychiatry 20: 254-260. DOI:10.1002/gps.1275.

Andrén S, Elmstâhl S. 2007. Relationships between income, subjective health and caregiver burden in caregivers of people with dementia in group living care: a cross-sectional community-based study. Int. J. Nurs. Stud. 44: 435-446. DOI:10.1016/j.ijnurstu.2006.08. 016.

Bastawrous M, Cignac MA, Kapral MK, Cameron JI. 2015. Factors that contribute to adult children caregivers’ well-being: a scoping review. Health Soc. Care Community 23: 449466. DOI:10.1111/hsc.12144.

Blesa R, Pujol M, Aguilar M, et al. 2001. Clinical validity of the “mini-mental state” for Spanish speaking communities. Neuropsychologia 39: 1150-1157. DOI:10.1016/ S0028-3932(01)00055-0.

Chappell NL, Dujela C, Smith A. 2014. Spouse and adult child differences in caregiving burden. Can. J. Aging 33: 462-472. DOI:10.1017/S0714980814000336.

Chappell NL, Dujela C, Smith A. 2015. Caregiver Well-Being: Intersections of Relationship and Gender. Res. Aging 37: 623-645. DOI:10.1177/0164027514549258.

Cohen J. 1973. Eta-squared and partial eta-squared in fixed factor ANOVA designs. Educ. Psychol. Meas. 33: 107-112. DOI:10.1177/001316447303300111.

Cohen J. 1988. Statistical power analysis for the behavioral sciences (2nd ed.). Lawrence Erlbaum: Hillsdale New Jersey. 
Conde-Sala JL, Garre-Olmo J, Turró-Garriga O, Vilalta-Franch J, López-Pousa S. 2010. Differential features of burden between spouse and adult-child caregivers of patients with Alzheimer's disease: An exploratory comparative design. Int. J. Nurs. Stud. 47: 12621273. DOI:10.1016/j.ijnurstu.2010.03.001.

Conde-Sala JL, Turró-Garriga O, Calvó-Perxas L, et al. 2014. Three-year trajectories of caregiver burden in Alzheimer’s disease. J. Alzheimers Dis. 42: 623-633. DOI:10.3233/ JAD-140360.

Cummings JL, Mega M, Gray K, et al. 1994. The neuropsychiatric inventory. Comprehensive assessment of psychopathology in dementia. Neurology 44: 2308-2314. DOI:10.1212/ WNL.44.12.2308.

Etters L, Goodall D, Harrison BE. 2008. Caregiver burden among dementia patient caregivers: a review of the literature. J. Am. Acad. Nurse Pract. 20: 423-428. DOI:10.1111/ j.1745-7599.2008.00342.x.

Ferrario SR, Vitaliano P, Zotti AM, Galante E, Fornara R. 2003. Alzheimer’s disease: usefulness of the Family Strain Questionnaire and the Screen for Caregiver Burden in the study of caregiving-related problems. Int. J. Geriatr. Psychiatry 18: 1110-1114. DOI: 10.1002/gps.1021.

Folstein MF, Folstein SE, McHugh PR. 1975. "Mini-Mental State”: A practical method for grading the cognitive state of patients for the clinician. J. Psychiatr. Res.12: 189-198. DOI: http://dx.doi.org/10.1016/0022-3956(75)90026-6.

Gélinas I, Gauthier L, McIntyre M, Gauthier S. 1999. Development of a functional measure for persons with Alzheimer's disease: the disability assessment for dementia. Am. J. Occup. Ther. 53: 471-481. DOI:10.5014/ajot.53.5.471.

Jurado MA, Mataró M, Pueyo R. 2013. Neuropsicología de las enfermedades neurodegenerativas. Editorial Síntesis: Madrid. 
Kim H, Chang M, Rose K, Kim S. 2012. Predictors of caregiver burden in caregivers of individuals with dementia. J. Adv. Nurs. 68: 846-855. DOI:10.1111/ j.1365-2648. 2011.05787.x.

Liang KY, Zeger SL. 1986. Longitudinal data analysis using generalized linear models. Biometrika 73: 13-22. DOI:10.1093/biomet/73.1.13.

Marwit SJ, Meuser TM. 2002. Development and initial validation of an inventory to assess grief in caregivers of persons with Alzheimer’s disease. Gerontologist 42: 751-765. DOI: 10.1093/geront/42.6.751.

McKhann GM, Knopman DS, Chertkow H, et al. 2011. The diagnosis of dementia due to Alzheimer's disease: recommendations from the National Institute on Aging-Alzheimer's Association workgroups on diagnostic guidelines for Alzheimer's disease. Alzheimers Dement. 7: 263-269. DOI:10.1016/j.jalz.2011.03.005.

Molyneux G, McCarthy GM, McEniff S, Gryan M, Conroy RM. 2008. Prevalence and predictors of carer burden and depression in carers of patients referred to an old age psychiatric service. Int. Psychogeriatr. 20: 1193-1202. DOI:10.1017/ S104161020800 7515.

Park M, Sung M, Kim SK, Kim S, Lee DY. 2015. Multidimensional determinants of family caregiver burden in Alzheimer’s disease. Int. Psychogeriatr. 27: 1355-1364. DOI: 10. 1017/ S1041610215000460.

Pattanayak RD, Jena R, Tripathi M, Khandelwal SK. 2010. Assessment of burden in caregivers of Alzheimer’s disease from India. Asian J. Psychiatr. 3: 112-116. DOI: 10.1016/j.ajp.2010.06.002.

Pinquart M, Sörensen S. 2011. Spouses, adult children, and children-in-law as caregivers of older adults: a meta-analytic comparison. Psychol. Aging 26: 1-14. DOI:10.1037/ a00218 63. 
Prince M, Wimo A, Guerchet M, et al. 2015. World Alzheimer Report 2015. The Global Impact of Dementia. An analysis of prevalence, incidence, cost and trends. Alzheimer's Disease International: London.

Raccichini A, Castellani S, Civerchia P, Fioravanti P, Scarpino O. 2009. The caregiver’s burden of Alzheimer patients: differences between live-in and non-live-in. Am. $J$. Alzheimers Dis. Other Demen. 24: 377-383. DOI:10.1177/1533317509340025.

Raccichini A, Spazzafumo L, Castellani S, et al. 2015. Living with mild to moderate Alzheimer patients increases the caregiver's burden at 6 months. Am. J. Alzheimers Dis. Other Demen. 30: 463-467. DOI:10.1177/1533317514568339.

Reed C, Belger M, Dell’Agnello G, et al. 2014. Caregivers Burden in Alzheimer's Disease: Differential Associations in Adult-Child and Spousal Caregivers in the GERAS Observational Study. Dement. Geriatr. Cogn. Dis. Extra 4: 51-64. DOI:10.1159/ 000358234.

Reisberg B, Ferris SH, De Leon MJ, Crook T. 1982. The Global Deterioration Scale for assessment of primary degenerative dementia. Am J Psychiatry 139: 1136-1139. DOI: 10.1176/ajp.139.9.1136.

Riedijk S, Duivenvoorden H, Rosso S, et al. 2008. Frontotemporal Dementia: Change of Familial Caregiver Burden and Partner Relation in a Dutch Cohort of 63 Patients. Dement. Geriatr. Cogn. Dis. 26: 398-406. DOI:10.1159/000164276.

Rinaldi P, Spazzafumo L, Mastriforti R, et al. 2005. Predictors of high level of burden and distress in caregivers of demented patients: results of an Italian multicenter study. Int. $J$. Geriatr. Psychiatry 20: 168-174. DOI:10.1002/gps.1267.

Robinson KM, Buckwalter KC, Reed D. 2005. Predictors of use of services among dementia caregivers. West. J. Nurs. Res. 27: 126-140. DOI:10.1177/0193945904272453. 
Sanders S, Ott CH, Kelber ST, Noonan P. 2008. The experience of high levels of grief in caregivers of persons with Alzheimer's disease and related dementia. Death Stud. 32: 495-523. DOI:10.1080/07481180802138845.

Schulz R, Martire LM. 2004. Family caregiving of persons with dementia: prevalence, health effects, and support strategies. Am. J. Geriatr. Psychiatry 12: 240-249. DOI:10.1097/ 00019442-200405000-00002.

Turró-Garriga O, Soler-Cors O, Garre-Olmo J, et al. 2008. Distribución factorial de la carga en cuidadores de pacientes con enfermedad de Alzheimer. Rev. Neurol. 46: 582-588.

Ware JJr, Kosinski M, Keller SD. 1996. A 12-Item Short-Form Health Survey: construction of scales and preliminary tests of reliability and validity. Med. Care 34: 220-233.

Winslow BW. 1997. Effects of Formal Supports on Stress Outcomes in Family Caregivers of Alzheimer's Patients. Res. Nurs. Health 20: 27-37. DOI: 10.1002/(SICI)1098-240X (199702)20:1<27::AID-NUR4>3.0.CO;2-W.

Wolfs CA, Kessels A, Severens JL, et al. 2012. Predictive factors for the objective burden of informal care in people with dementia: a systematic review. Alzheimer Dis. Assoc. Disord. 26: 197-204. DOI:10.1097/WAD.0b013e31823a6108.

Wong CC, Wallhagen MI. 2012. Frontotemporal dementia: the impact of patient behavioral symptoms on the physical and mental health of family caregivers. Dement. Geriatr. Cogn. Dis. Extra 2: 516-528. DOI:10.1159/000345082.

Zarit SH, Todd PA, Zarit JM. 1986. Subjective burden of husbands and wives as caregiver: a longitudinal study. Gerontologist 26: 260-266. DOI:10.1093/geront/26.3.260.

Zeger SL, Liang KY, Albert PS. 1988. Models for longitudinal data: a generalized estimating equation approach. Biometrics 44: 1049-1060. DOI: 10.2307/2531734. 


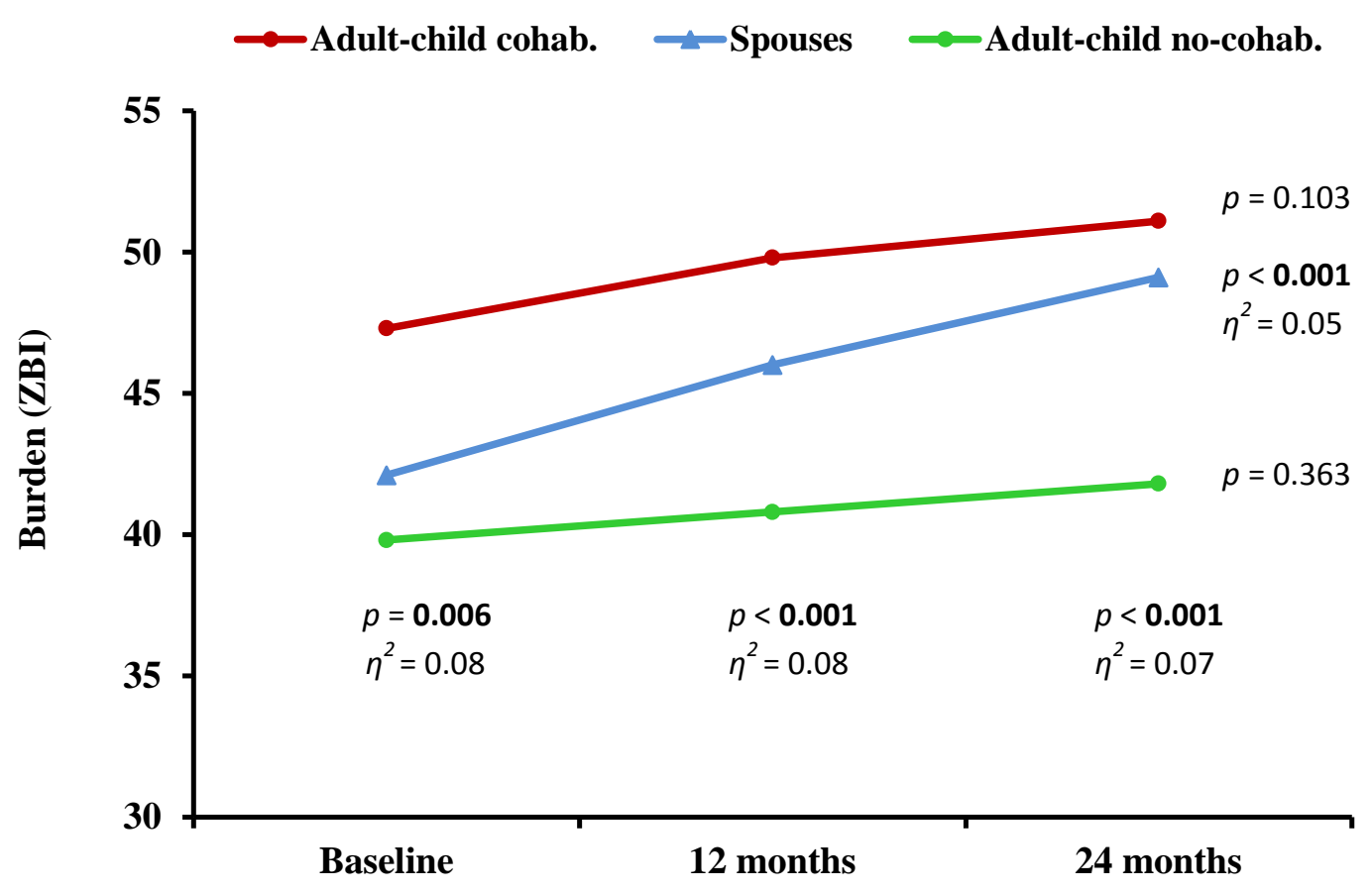

Fig. 1. Burden on family caregivers groups.

Generalized Estimating Equations Wald $\chi^{2} ; \eta^{2}=$ Effect size 
Kinship and cohabitation in caregiver burden

Table 1 Comparison (at baseline) of the two groups

\begin{tabular}{|c|c|c|c|c|c|}
\hline & \multirow{2}{*}{$\frac{\text { Study participants }}{(n=275)}$} & \multirow{2}{*}{$\frac{\text { Lost to follow-up }}{(n=230)}$} & \multicolumn{3}{|c|}{ Differences } \\
\hline & & & Test $(d f)$ & $p$ & $d / V$ \\
\hline \multicolumn{6}{|l|}{ Caregiver factors } \\
\hline Age (years) & $63.2 \pm 13.3$ & $60.2 \pm 14.5$ & $2.41^{\mathrm{a}}$ & 0.016 & 0.21 \\
\hline Women (\%) & $180(65.5)$ & $156(67.8)$ & $0.31(1)^{b}$ & 0.574 & 0.02 \\
\hline Education $\geq 8$ years $(\%)$ & $43(34.7)$ & $33(40.2)$ & $0.65(1)^{b}$ & 0.418 & 0.05 \\
\hline \multicolumn{6}{|l|}{ Relationship with patient (\%) } \\
\hline Spouses & $153(55.7)$ & $101(43.9)$ & $7.83(2)^{b}$ & 0.020 & 0.12 \\
\hline Adult-child cohabiting & $54(19.6)$ & $65(28.3)$ & & & \\
\hline Adult-child non-cohabiting & $68(24.7)$ & $64(27.8)$ & & & \\
\hline ZBI (burden) & $42.6 \pm 13.4$ & $46.3 \pm 15.3$ & $2.55^{\mathrm{a}}$ & 0.011 & 0.25 \\
\hline SF-12 (physical health) & $48.7 \pm 10.3$ & $48.9 \pm 9.6$ & $0.13^{\mathrm{a}}$ & 0.891 & 0.02 \\
\hline SF-12 (mental health) & $45.3 \pm 11.6$ & $44.5 \pm 11.7$ & $0.90^{\mathrm{a}}$ & 0.364 & 0.06 \\
\hline \multicolumn{6}{|l|}{ PwD factors } \\
\hline Age (years) & $76.8 \pm 6.8$ & $78.8 \pm 6.7$ & $3.59^{\mathrm{a}}$ & $<\mathbf{0 . 0 0 1}$ & 0.29 \\
\hline Women (\%) & $173(62.9)$ & $146(63.5)$ & $0.01(1)^{b}$ & 0.895 & 0.00 \\
\hline Education $\geq 6$ years $(\%)$ & $127(46.2)$ & $119(51.7)$ & $1.54(1)^{b}$ & 0.213 & 0.05 \\
\hline MMSE (cognition) & $18.9 \pm 4.3$ & $16.9 \pm 5.1$ & $4.47^{\mathrm{a}}$ & $<\mathbf{0 . 0 0 1}$ & 0.42 \\
\hline DAD (ADL) & $64.9 \pm 9.9$ & $61.2 \pm 10.1$ & $4.10^{\mathrm{a}}$ & $<\mathbf{0 . 0 0 1}$ & 0.36 \\
\hline NPI (behavioural) & $14.6 \pm 14.8$ & $19.8 \pm 19.4$ & $3.17^{\mathrm{a}}$ & 0.001 & 0.30 \\
\hline \multicolumn{6}{|l|}{ GDS (stages) } \\
\hline 4 (moderate) & $179(65.1)$ & 101 (43.9) & $28.44(2)^{b}$ & $<0.001$ & 0.23 \\
\hline 5 (moderate-severe) & $74(26.9)$ & $80(34.8)$ & & & \\
\hline 6 (severe) & $22(8.0)$ & $49(21.3)$ & & & \\
\hline
\end{tabular}

\footnotetext{
${ }^{\mathrm{a}}$ Mann-Whitney $U$ test; ${ }^{\mathrm{b}}$ Pearson $\chi^{2}$ test.; $d$, Cohen's d for means, small effect $(<0.5)$; V, Cramer's for categorical variables, $d f 2$, weak $(<0.20)$, moderate $(0.21-0.34)$; $p$-values $<0.05$ are shown in bold.

MMSE, Mini Mental State Examination; ADL, Activities of Daily Living; DAD, Disability Assessment for Dementia; NPI, Neuropsychiatric Inventory; ZBI, Zarit Burden Interview; SF-12, Short Form of Health Survey; GDS, Global Deterioration Scale.
} 
Kinship and cohabitation in caregiver burden

Table 2 Caregivers’ socio-demographic data. Spouse, adult-child (cohabiting/non-cohabiting)

\begin{tabular}{|c|c|c|c|}
\hline & \multirow{2}{*}{$\begin{array}{c}\text { Baseline } \\
n=275 \\
n \quad \%\end{array}$} & \multirow{2}{*}{$\begin{array}{c}12 \text { months } \\
n=275 \\
n \quad \%\end{array}$} & \multirow{2}{*}{$\begin{array}{l}24 \text { months } \\
n=275 \\
n \quad \%\end{array}$} \\
\hline & & & \\
\hline \multicolumn{4}{|l|}{ Relationship with the patient } \\
\hline Spouse & 153 (55.7) & $149(54.2)$ & $148(53.8)$ \\
\hline Adult-child cohabiting & 54 (19.6) & $58(21.1)$ & $56(20.4)$ \\
\hline Adult-child non-cohabiting & $68(24.7)$ & 68 (24.7) & $71(25.8)$ \\
\hline$\chi^{2}(d f) p, V$ & $0.3(4), 0.988,0.01$ & & \\
\hline \multicolumn{4}{|l|}{ Age (mean, SD) } \\
\hline Spouses & $73.2(6.7)$ & $73.7(7.4)$ & $74.4(8.5)$ \\
\hline 1. Adult-child cohabiting & $51.8(7.5)$ & $53.1(7.2)$ & $53.6(7.4)$ \\
\hline 2. Adult-child non-cohabiting & $49.5(7.6)$ & $50.2(7.8)$ & $51.5(8.4)$ \\
\hline Kruskal Wallis $(d f) p, d(1-2)$ & $195.7(2)<\mathbf{0 . 0 0 1}, 0.30$ & $188.0(2)<\mathbf{0 . 0 0 1}, 0.38$ & $183.4(2)<\mathbf{0 . 0 0 1}, 0.26$ \\
\hline \multicolumn{4}{|l|}{ Gender (women) } \\
\hline Spouse & $84(54.9)$ & $82(55.0)$ & $82(55.4)$ \\
\hline Adult-child cohabiting & $41(75.9)$ & $48(82.8)$ & $48(85.7)$ \\
\hline Adult-child non-cohabiting & $51(75.0)$ & $50(75.0)$ & $54(76.1)$ \\
\hline$\chi^{2}(d f) p, V$ & $12.4(2) \mathbf{0 . 0 0 2}, 0.21$ & $14.1(2) \mathbf{0 . 0 0 1}, 0.22$ & $20.4(2)<\mathbf{0 . 0 0 1}, 0.27$ \\
\hline \multicolumn{4}{|l|}{ Education ( $>8$ years) } \\
\hline Spouse & $28(18.3)$ & $21(14.1)$ & $19(12.8)$ \\
\hline Adult-child cohabiting & $33(61.1)$ & $36(62.1)$ & $32(57.1)$ \\
\hline Adult-child non-cohabiting & $48(70.6)$ & $52(76.5)$ & $50(70.4)$ \\
\hline$\chi^{2}(d f) p, V$ & $66.7(2)<\mathbf{0 . 0 0 1}, 0.49$ & $91.3(2)<\mathbf{0 . 0 0 1}, 0.57$ & $81.0(2)<\mathbf{0 . 0 0 1}, 0.54$ \\
\hline \multicolumn{4}{|l|}{ Sole caregiver (Yes) } \\
\hline Spouse & $134(87.6)$ & $133(89.3)$ & $119(80.4)$ \\
\hline Adult-child cohabiting & $33(61.1)$ & $36(62.1)$ & $36(64.3)$ \\
\hline Adult-child non-cohabiting & $28(41.2)$ & $27(39.7)$ & $18(25.4)$ \\
\hline$\chi^{2}(d f) p, V$ & $52.2(2)<\mathbf{0 . 0 0 1}, 0.43$ & $59.0(2)<\mathbf{0 . 0 0 1}, 0.46$ & $62.3(2)<\mathbf{0 . 0 0 1}, 0.47$ \\
\hline \multicolumn{4}{|l|}{ Care resources (Yes) } \\
\hline Spouse & $39(25.5)$ & $53(35.6)$ & $60(40.5)$ \\
\hline Adult-child cohabiting & $15(27.8)$ & $21(36.2)$ & $26(46.4)$ \\
\hline Adult-child non-cohabiting & 27 (39.7) & $34(50.0)$ & 39 (54.9) \\
\hline$\chi^{2}(d f) p, V$ & 4.6 (2) $0.097,0.13$ & 4.3 (2) $0.133,0.12$ & 4.0 (2) $0.133,0.12$ \\
\hline \multicolumn{4}{|l|}{ Marital status (married) } \\
\hline Adult-child cohabiting & $31(57.4)$ & $31(53.4)$ & $32(57.1)$ \\
\hline Adult-child non-cohabiting & $51(75.0)$ & $56(82.4)$ & 55 (77.5) \\
\hline$\chi^{2}(d f) p, V$ & 4.2 (1) $\mathbf{0 . 0 4 0}, 0.18$ & $12.2(1)<\mathbf{0 . 0 0 1}, 0.31$ & 5.9 (1) $\mathbf{0 . 0 1 4}, 0.27$ \\
\hline \multicolumn{4}{|l|}{ Children at home } \\
\hline Adult-child cohabiting & $18(33.3)$ & $29(50.0)$ & 22 (39.3) \\
\hline Adult-child non-cohabiting & 36 (52.9) & 39 (57.4) & $34(47.9)$ \\
\hline$\chi^{2}(d f) p, V$ & 4.6 (1) 0.030, 0.19 & $0.6(1) 0.408,0.07$ & 0.9 (1) $0.332,0.08$ \\
\hline \multicolumn{4}{|l|}{ Work outside the home } \\
\hline Adult-child cohabiting & $35(64.8)$ & 35 (60.3) & $30(53.6)$ \\
\hline Adult-child non-cohabiting & $47(69.1)$ & $46(67.6)$ & $45(63.4)$ \\
\hline$\chi^{2}(d f) p, V$ & 0.2 (1) $0.615,0.04$ & 0.7 (1) $0.394,0.07$ & $1.2(2) 0.264,0.09$ \\
\hline
\end{tabular}

$\chi^{2}$, Chi-square test for categorical variables; Effect size: $V=$ Cramer's (df1= small: $\leq 0.10$, medium: 0.11-0.49, large: $\geq 0.50$; df2 = small: $\leq 0.07$, medium: $0.08-0.34$, large: $\geq 0.35 ; d$, Cohen's $\mathrm{d}$ (small $=0.2$, medium $=0.5$, large $=0.8) ; p$-values $<0.05$ are shown in bold. 
Kinship and cohabitation in caregiver burden

Table 3 Caregivers' clinical data. Spouse, adult-child (cohabiting/non-cohabiting)

\begin{tabular}{|c|c|c|c|c|c|c|}
\hline & \multirow{2}{*}{$\begin{array}{l}\text { Baseline } \\
\frac{1(n=275)}{\text { Mean (SE) }}\end{array}$} & \multirow{2}{*}{$\begin{array}{l}12 \text { months } \\
\frac{2(n=275)}{\text { Mean }(\mathrm{SE})}\end{array}$} & \multirow{2}{*}{$\begin{array}{l}24 \text { months } \\
\frac{3(n=275)}{\text { Mean (SE) }}\end{array}$} & \multicolumn{3}{|c|}{ Simple effects } \\
\hline & & & & $\chi^{2}$ & $(d f)$ & $p$ \\
\hline \multicolumn{7}{|l|}{ Mental health (SF-12) } \\
\hline Spouses & $45.7(0.9)$ & $44.8(1.0)$ & $43.8(0.9)$ & 2.5 & 2 & 0.277 \\
\hline Adult-child cohabiting & $43.2(1.5)$ & $43.2(1.4)$ & $42.2(1.5)$ & 0.1 & 2 & 0.929 \\
\hline Adult-child non-cohabiting & $46.4(1.3)$ & $45.4(1.2)$ & $45.7(1.4)$ & 0.0 & 2 & 0.974 \\
\hline Simple effects $\chi^{2}(d f) p$ & $3.2(2) 0.198$ & $2.3(2) 0.305$ & 3.7 (2) 0.155 & & & \\
\hline - Model effects $\chi^{2}(d f) p$ & \multicolumn{6}{|c|}{ Time $=1.9(2) 0.369 ;$ Groups $=3.8(2) 0.149 ;$ Time $*$ groups $=0.9(4) 0.914$} \\
\hline \multicolumn{7}{|l|}{ Physical health (SF-12) } \\
\hline Spouses & $46.3(0.8)$ & $46.1(0.9)$ & $44.6(0.9)$ & 4.3 & 2 & 0.116 \\
\hline Adult-child cohabiting & $53.5(1.0)^{d}$ & $51.8(1.3)^{d}$ & $52.3(1.2)^{d}$ & 2.8 & 2 & 0.238 \\
\hline Adult-child non-cohabiting & $50.3(1.1)^{\mathrm{e}}$ & $51.4(0.9)^{\mathrm{e}}$ & $50.3(1.0)^{\mathrm{e}}$ & 2.2 & 2 & 0.328 \\
\hline Simple effects $\chi^{2}(d f) p$ & $26.5(2)<\mathbf{0 . 0 0 1}$ & $19.5(2)<\mathbf{0 . 0 0 1}$ & $30.5(2)<\mathbf{0 . 0 0}$ & & & \\
\hline - Model effects $\chi^{2}(d f) p$ & \multicolumn{6}{|c|}{ Time $=2.9(2) 0.225 ;$ Groups $=33.5(2)<\mathbf{0 . 0 0 1} ;$ Time* groups $=4.1$ (4) 0.387} \\
\hline \multicolumn{7}{|l|}{ Burden (ZBI) } \\
\hline Spouses & $42.1(0.9)$ & $46.0(1.1)^{\mathrm{a}}$ & $49.1(1.2)^{\mathrm{b}, \mathrm{c}}$ & 45.8 & $2<$ & $<\mathbf{0 . 0 0 1}$ \\
\hline Adult-child cohabiting & $47.3(1.9)^{\mathrm{d}}$ & $49.8(1.9)$ & $51.1(1.9)$ & 4.5 & 2 & 0.103 \\
\hline Adult-child non-cohabiting & $39.8(1.4)^{\mathrm{f}}$ & $40.8(1.4)^{\mathrm{e}, \mathrm{f}}$ & $41.8(1.6)^{e, f}$ & 2.0 & 2 & 0.363 \\
\hline Simple effects $\chi^{2}(d f) p$ & $10.3(2) 0.006$ & $15.5(2)<\mathbf{0 . 0 0 1}$ & $16.7(2)<\mathbf{0 . 0 0}$ & & & \\
\hline - Model effects $\chi^{2}(d f) p$ & \multicolumn{6}{|c|}{ Time $=28.0(2)<\mathbf{0 . 0 0 1} ;$ Groups $=18,0(2)<\mathbf{0 . 0 0 1} ;$ Time $*$ groups $=8.5(4) 0.074$} \\
\hline
\end{tabular}

Generalized Estimating Equations Wald $\chi^{2}$; Means, estimated marginal; SE, standard error;

Significant with Bonferroni post hoc contrasts: ${ }^{\mathrm{a}} 1-2,{ }^{\mathrm{b}} 1-3,{ }^{\mathrm{c}} 2-3,{ }^{\mathrm{d}}$ Spouses /adult-child cohabiting, ${ }^{\mathrm{e}}$

Spouses/adult child non-cohabiting, ${ }^{\mathrm{f}}$ Adult-child cohabiting/non-cohabiting; $p$-values $<0.05$ are shown in bold.

SF-12, Short Form of Health Survey; ZBI, Zarit Burden Interview. 
Kinship and cohabitation in caregiver burden

Table 4 Multivariate analysis. Burden (ZBI). Time \& factors of caregivers. Adjusted for clinical data of patients (MMSE, DAD and NPI)

\begin{tabular}{|c|c|c|c|c|c|c|c|c|c|c|c|c|}
\hline & \multicolumn{3}{|c|}{ Model effects } & \multicolumn{7}{|c|}{ Parameter estimates } & & \\
\hline & \multirow[b]{2}{*}{$\chi^{2}$} & \multirow[b]{2}{*}{$d f$} & \multirow[b]{2}{*}{$p$} & \multicolumn{3}{|l|}{ Baseline } & \multicolumn{3}{|l|}{12 months } & \multicolumn{3}{|l|}{24 months } \\
\hline & & & & $\mathrm{B}(\mathrm{SE})$ & $\chi^{2}$ & $p$ & $\overline{\mathrm{B}(\mathrm{SE})}$ & $\chi^{2}$ & $p$ & $\overline{B(S E)}$ & $\chi^{2}$ & $p$ \\
\hline Mental Health (SF-12) & 145.7 & 9 & $<0.001$ & & & & & & & & & \\
\hline Spouses & & & & $-0.21(0.06)$ & 9.6 & 0.002 & $-0.26(0.06)$ & 19.0 & $<0.001$ & $-0.42(0.06)$ & 40.4 & $<0.001$ \\
\hline Adult-child cohabit & & & & $-0.43(0.11)$ & 15.8 & $<0.001$ & $-0.59(0.08)$ & 50.9 & $<0.001$ & $-0.67(0.11)$ & 34.3 & $<0.001$ \\
\hline Adult-child non-cohabit & & & & $-0.38(0.09)$ & 15.0 & $<0.001$ & $-0.47(0.10)$ & 19.2 & $<0.001$ & $-0.44(0.08)$ & 29.2 & $<0.001$ \\
\hline Physical health (SF-12) & 37.5 & 9 & $<0.001$ & & & & & & & & & \\
\hline Spouses & & & & $-0.07(0.06)$ & 1.4 & 0.233 & $-0.20(0.05)$ & 12.2 & $<0.001$ & $-0.16(0.05)$ & 7.8 & 0.005 \\
\hline Adult-child cohabit & & & & $-0.13(0.18)$ & 0.5 & 0.468 & $0.06(0.10)$ & 0.3 & 0.528 & $-0.02(0.09)$ & 0.0 & 0.794 \\
\hline Adult-child non-cohabit & & & & $-0.36(0.10)$ & 12.4 & $<0.001$ & $-0.31(0.11)$ & 7.1 & 0.008 & $-0.00(0.11)$ & 0.0 & 0.967 \\
\hline Care resources $(-=$ yes $)$ & 21.4 & 9 & 0.011 & & & & & & & & & \\
\hline Spouses & & & & $0.83(1.50)$ & 0.3 & 0.581 & $4.03(1.50)$ & 7.1 & 0.007 & $3.18(1.46)$ & 4.7 & 0.030 \\
\hline Adult-child cohabit & & & & $7.32(2.48)$ & 8.6 & 0.003 & 1.46 (1.98) & 0.5 & 0.459 & $2.26(3.08)$ & 0.5 & 0.463 \\
\hline Adult-child non-cohabit & & & & $1.12(3.34)$ & 0.1 & 0.738 & $-0.12(2.17)$ & 0.0 & 0.953 & $-3.91(2.25)$ & 3.0 & 0.082 \\
\hline Age (years) & 21.1 & 9 & 0.012 & & & & & & & & & \\
\hline Spouses & & & & $-0.08(0.08)$ & 0.9 & 0.318 & $-0.04(0.06)$ & 0.4 & 0.493 & $0.02(0.06)$ & 0.1 & 0.725 \\
\hline Adult-child cohabit & & & & $0.20(0.13)$ & 2.3 & 0.127 & $0.16(0.12)$ & 1.6 & 0.200 & $0.17(0.13)$ & 1.6 & 0.202 \\
\hline Adult-child non-cohabit & & & & $0.35(0.13)$ & 7.4 & 0.007 & $-0.06(0.10)$ & 0.4 & 0.521 & $0.27(0.11)$ & 5.8 & 0.015 \\
\hline $\operatorname{Sex}(-=\operatorname{men})$ & 19.5 & 9 & 0.021 & & & & & & & & & \\
\hline Spouses & & & & $-1.67(1.32)$ & 1.6 & 0.206 & $-0.36(1.50)$ & 0.0 & 0.811 & $1.63(1.47)$ & 1.2 & 0.267 \\
\hline Adult-child cohabit & & & & $-7.14(3.15)$ & 5.1 & 0.024 & $-1.96(3.40)$ & 0.3 & 0.564 & $4.12(3.65)$ & 1.2 & 0.260 \\
\hline Adult-child non-cohabit & & & & $-1.82(3.07)$ & 0.3 & 0.552 & $2.64(1.89)$ & 1.9 & 0.162 & $-3.55(2.33)$ & 2.3 & 0.129 \\
\hline Sole caregiver $(-=$ yes $)$ & 17.8 & 9 & 0.035 & & & & & & & & & \\
\hline Spouses & & & & $1.60(1.96)$ & 0.6 & 0.415 & $-1.41(1.44)$ & 0.9 & 0.327 & $-1.59(1.46)$ & 1.1 & 0.276 \\
\hline Adult-child cohabit & & & & $-0.69(2.59)$ & 0.0 & 0.788 & $-4.38(1.99)$ & 4.8 & 0.028 & $-8.72(2.76)$ & 9.9 & 0.002 \\
\hline Adult-child non-cohabit & & & & $0.55(2.33)$ & 0.0 & 0.813 & $-2.03(1.97)$ & 1.0 & 0.302 & $-6.43(3.00)$ & 4.5 & 0.032 \\
\hline
\end{tabular}

Burden (ZBI) as dependent variable. Generalized Estimating Equations, Wald $\chi^{2}$; B, Beta coefficient; SE, standard error; $p$-values $<0.05$ are shown in bold.

MMSE, Mini Mental State Examination; ADL, Activities of Daily Living; DAD, Disability Assessment for Dementia; NPI, Neuropsychiatric

Inventory; ZBI, Zarit Burden Interview; SF-12, Short Form of Health Survey. 
Kinship and cohabitation in caregiver burden

Table 5 Factorial analysis of burden. Spouse, adult-child (cohabiting/non-cohabiting)

\begin{tabular}{|c|c|c|c|c|c|c|}
\hline \multirow[b]{2}{*}{ Factorial Burden (ZBI) } & \multirow{2}{*}{$\begin{array}{l}\text { Baseline } \\
\frac{1(n=275)}{\text { Mean (SE) }}\end{array}$} & \multirow{2}{*}{$\begin{array}{l}12 \text { months } \\
2(n=275) \\
\text { Mean }(\mathrm{SE})\end{array}$} & \multirow{2}{*}{$\begin{array}{l}24 \text { months } \\
\frac{3(n=275)}{\text { Mean (SE) }}\end{array}$} & \multicolumn{3}{|c|}{ Simple effects } \\
\hline & & & & $\chi^{2}$ & $(d f)$ & $p$ \\
\hline \multicolumn{7}{|l|}{ Social and physical (F1) } \\
\hline Spouses & $16.0(0.8)$ & $18.2(1.0)^{\mathrm{a}}$ & $19.9(1.0)^{\mathrm{b}}$ & 13.5 & 2 & 0.001 \\
\hline Adult-child cohabiting & $19.5(1.5)$ & $23.2(1.5)^{a, d}$ & $23.6(1.6)^{b}$ & 9.6 & 2 & 0.008 \\
\hline Adult-child non-cohabiting & $15.2(1.4)$ & $17.0(1.4)^{e, f}$ & $16.6(1.7)^{f}$ & 2.1 & 2 & 0.347 \\
\hline Simple effects $\chi^{2}(d f) p$ & 5.9 (2) 0.052 & 12.9 (2) 0.002 & 11.9 (2) 0.003 & & & \\
\hline - Model effects $\chi^{2}(d f) p$ & \multicolumn{6}{|c|}{ Time $=19.5(2)<\mathbf{0 . 0 0 1} ;$ Groups $=13.4(2) \mathbf{0 . 0 0 1} ;$ Time $^{*}$ groups $=4.9(4) 0.29$} \\
\hline \multicolumn{7}{|l|}{ Anxiety (F2) } \\
\hline Spouses & $6.9(0.3)$ & $7.5(0.3)$ & $7.5(0.4)$ & 3.9 & 2 & 0.139 \\
\hline Adult-child cohabiting & $7.5(0.5)$ & $7.2(0.5)$ & $7.3(0.5)$ & 0.1 & 2 & 0.906 \\
\hline Adult-child non-cohabiting & $7.0(0.5)$ & $7.7(0.5)$ & $8.4(0.6)$ & 4.3 & 2 & 0.113 \\
\hline Simple effects $\chi^{2}(d f) p$ & $0.9(2) 0.614$ & $0.4(2) 0.815$ & $2.0(2) 0.359$ & & & \\
\hline - Model effects $\chi^{2}(d f) p$ & \multicolumn{6}{|c|}{ Time $=3.2(2) 0.201 ;$ Groups $=0.6(2) 0.716 ;$ Time* groups $=3.4(4) 0.488$} \\
\hline \multicolumn{7}{|l|}{ Guilt (F3) } \\
\hline Spouses & $2.5(0.1)$ & $2.6(0.1)$ & $2.6(0.1)$ & 0.5 & 2 & 0.767 \\
\hline Adult-child cohabiting & $3.3(0.3)$ & $2.8(0.3)$ & $2.6(0.3)$ & 3.6 & 2 & 0.165 \\
\hline Adult-child non-cohabiting & $3.3(0.3)$ & $3.2(0.2)$ & $3.2(0.3)$ & 0.0 & 2 & 0.975 \\
\hline Simple effects $\chi^{2}(d f) p$ & 5.0 (2) 0.079 & $3.2(2) 0.200$ & 2.1 (2) 0.348 & & & \\
\hline - Model effects $\chi^{2}(d f) p$ & \multicolumn{6}{|c|}{ Time $=1.5(2) 0.462 ;$ Groups $=4.7$ (2) 0.094; Time* groups $=4.5$ (4) 0.338} \\
\hline \multicolumn{7}{|l|}{ Irritation (F4) } \\
\hline Spouses & $5.3(0.2)$ & $6.4(0.2)^{\mathrm{a}}$ & $6.5(0.3)^{b}$ & 15.9 & 2 & $<0.001$ \\
\hline Adult-child cohabiting & $5.6(0.4)$ & $6.0(0.4)$ & $6.9(0.4)^{b}$ & 6.5 & 2 & 0.037 \\
\hline Adult-child non-cohabiting & $5.1(0.4)$ & $5.3(0.3)^{e}$ & $5.6(0.3)$ & 1.2 & 2 & 0.534 \\
\hline Simple effects $\chi^{2}(d f) p$ & 0.7 (2) 0.674 & 5.7 (2) 0.056 & $6.2(2) 0.044$ & & & \\
\hline - Model effects $\chi^{2}(d f) p$ & \multicolumn{6}{|c|}{ Time $=14.8$ (2) 0.001; Groups $=6.5$ (2) $\mathbf{0 . 0 3 8 ;}$ Time* groups $=4.2$ (4) 0.373} \\
\hline \multicolumn{7}{|l|}{ Dependence (F5) } \\
\hline Spouses & $13.6(0.3)$ & $14.0(0.3)$ & $14.0(0.3)$ & 1.6 & 2 & 0.431 \\
\hline Adult-child cohabiting & $12.8(0.6)$ & $13.1(0.4)$ & $12.6(0.5)$ & 0.9 & 2 & 0.635 \\
\hline Adult-child non-cohabiting & $12.3(0.7)$ & $12.5(0.6)$ & $11.8(0.7)^{\mathrm{e}}$ & 1.1 & 2 & 0.575 \\
\hline Simple effects $\chi^{2}(d f) p$ & 2.8 (2) 0.239 & $5.2(2) 0.073$ & 8.9 (2) 0.011 & & & \\
\hline - Model effects $\chi^{2}(d f) p$ & \multicolumn{6}{|c|}{ Time $=1.9$ (2) 0.373; Groups $=9.4(2)$ 0.009; Time* groups $=1.4$ (4) 0.830} \\
\hline
\end{tabular}

Generalized Estimating Equation Wald $\chi^{2}$; Means, estimated marginal; SE, standard error.

Significant with Bonferroni post hoc contrasts: ${ }^{\mathrm{a}} 1-2,{ }^{\mathrm{b}} 1-3,{ }^{\mathrm{c}} 2-3,{ }^{\mathrm{d}}$ Spouses/adult-child cohabiting, ${ }^{\mathrm{e}}$ Spouses/adult-child non-cohabiting, ${ }^{\mathrm{f}}$ Adult-child cohabiting/non-cohabiting; $p$-values $<0.05$ are shown in bold.

ZBI, Zarit Burden Interview. Factorial structure of the burden (ZBI) according to Turró-Garriga et al. (2008). Factor 1 (items 2, 3, 6, 10, 11, 12, 13, 17), Factor 2 (items 15, 16, 18, 19), Factor 3 (items 20, 21), Factor 4 (items 4, 5, 9), Factor $5(1,7,8,14)$. 